\title{
Service Quality and Customers' Satisfaction in Addis Ababa Light Rail Transit: Context, Relationships and Effect
}

\author{
Belayneh Bogale Zewdie \\ Lecturer, Department of Management, Kotebe Metropolitan University
}

\begin{abstract}
The issue of urban mass transportation is becoming the center of cites sustainable development and revitalization strategies. Hence, conducting a scientific inquiry into customers' satisfaction and service quality in urban light rail transport is vital to make policies and intervention measures instrumental and valid. Thus, the aim of this study is to assess service quality and customer satisfaction in urban transport service delivery with particular reference to Addis Ababa Light Rail Transit. To this end, dimensions as adopted in modified SERVPERF model have been utilized as measurement constructs and a quantitative approach has been employed. The study is a descriptive and explanatory type involving the analysis of data collected through questionnaire from passengers of the light Rail Transit. In order to analyze background information of respondents and their perception on service quality descriptive statistics is applied. Besides, the study has utilized correlation and regression analysis. The finding of the study shows that the customers are moderately satisfied with assurance and responsiveness while they are dissatisfied on affordability, tangibility, reliability and empathy. The correlation analysis of service quality dimensions (tangibility, reliability, responsiveness, assurance, empathy, and affordability) shows, they all are positively correlated to overall service quality. Besides, all service quality dimensions have a significant effect on customer satisfaction implying that the higher the quality of service, the higher is the level of customers' satisfaction. In conclusion, it is clear that Addis Ababa light rail transit can improve customers' satisfaction by working on quality.
\end{abstract}

Keywords: services, quality, customer satisfaction, light rail and SERVPREF

DOI: $10.7176 / \mathrm{EJBM} / 13-5-02$

Publication date:March $31^{\text {st }} 2021$

\section{Introduction}

The urban transport sector is an important component of the economy and a common tool used for development. Economic opportunities have been increasingly related to the mobility of people, goods, and information. When transport systems are efficient, they provide economic and social opportunities and benefits that result in positive multiplier effects such as better accessibility to markets, employment, and additional investments (Rodrigue, 2017). As World Bank (2008) states, "[---] cities are the engines of economic growth in most developing countries, and that urban transport is the oil that prevents the engine from seizing up" (p, 22). Improvement in transportation can make cities much more efficient and productive.

According to Peter (2006), the earlier transport policies of the developed countries were oriented to automobile developments. However, because of environmental and financial issues, the concept of sustainable mobility became a trend and led to new policies for mobility in cities. Due to increased travel demands, struggle for space and livability in the cities, growing carbon emissions from the transport sector, and the need to enhance mobility, a new transportation system called Light Rail System, was developed (Peter, 2006). The Light Rail system is used in both developed and developing countries in the last decades. It is documented that in European countries such as United Kingdom, France, Spain, Portugal, and Italy, and also in many cities in Asia, Latin America, and Africa (like Algeria, Egypt and Tunisia), light rail systems have been popular.

The city of Addis Ababa is the diplomatic center of Africa, and the seat for many international organizations. Addis is responsible for 60 percent of the country's industrial production and 50 percent of its GDP (Wondifiraw et al., 2015; WB, 2015). Therefore, the role of transport in running economic, social, and political activities, of the city, smoothly could not be easily valued.

Most trips in Addis Ababa are carried out using public transport and on foot. Sixty percent (60\%) of the population are walkers (SABA, 2005). The major modes of public transportation in Addis Ababa are buses, taxis, and light rail. Transportation service is being delivered to the public through public buses (Anbesa and Sheger), and other privately owned vehicles, such as higer buses, small buses, taxis, and the Addis Ababa light rail transit service.

The limited number of buses and taxis in Addis Ababa has resulted in low quality, safety, and accessibility of the service delivery across the city (Berhan et al., 2013; Kumar and Barrett, 2008). Users are hardly able to access public transport during peak hours or bad weather conditions (Fenta, 2014). Sometimes the commuters are required to pay an extra fare or forced to disembark when only mid-way through their route (Gebeyehu \& Takano, 2007; Kumar \& Barrett, 2008). This has resulted in customer dissatisfaction in general.

On the other hand, the population of Addis Ababa is increasing significantly and the number of people who 
work in the city and reside out of the city has been increasing over time. As the population increases, the number of passengers using public transport also increases. To accommodate the increasing number of passengers, the transport service is expected to expand. However, the supply of transport services is not proportional to demand. Due to the limited numbers of mass transport options, poor people who cannot afford other modes of transport are exposed to walk long distances, and longer waiting and travel time (SABA, 2005).

As one component of the Ethiopian growth and transformation plan (GTP I), the government launched Addis Ababa Light Rail Transit (AA-LRT) back in September 2015 to alleviate the transportation problem in the city. Despite all its contribution, based on casual observations and the available limited studies, (Haileyesus, 2016; Habtamu, 2017) during peak hours, the demand of light rail transport extremely exceeds the supply of service resulting longer waiting time and hard struggle to get the service. Moreover, trains are often overcrowded, which expose passengers to accidents, suffocation, a possible pick pocketing, and communicable diseases. This has made it difficult for the elderly, pregnant, patient, and disabled service seekers to use. However, most of the previous studies failed to measure the level of customers' satisfaction in urban light rail passenger service scientifically.

Therefore, whether customers are satisfied with the services provided by AA-LRT is a critical knowledge gap that needs to be addressed. Failure to conduct a scientific satisfaction and quality survey, and use the finding as input for decision making may jeopardize the improvement of the service. Thus, this study was carried out to investigate service quality and customers' satisfaction in urban transport service delivery with particular emphasis on Addis Ababa Light Rail Transit (AA-LRT).

To this end, literature availed several models for measuring service quality. SERVQUAL and SERVPERF are among the models which researcher are using most often. Both models use five service quality dimensions and empirical studies also show that service quality dimensions have relations with service quality. However, some studies have applied a certain pragmatic modification of the models. SERVPERF model is an improvised model of Parasurman's SERVQUAL. While SERVPERF dwells perceived service quality, the SERVQUAL approach has got to elements-expectation and perception. Having reviewed both theories and empirical studies on service quality and customer satisfaction, the following conceptual framework, modified SERVPERF, is developed for this study.

Fig 1: Conceptual Framework

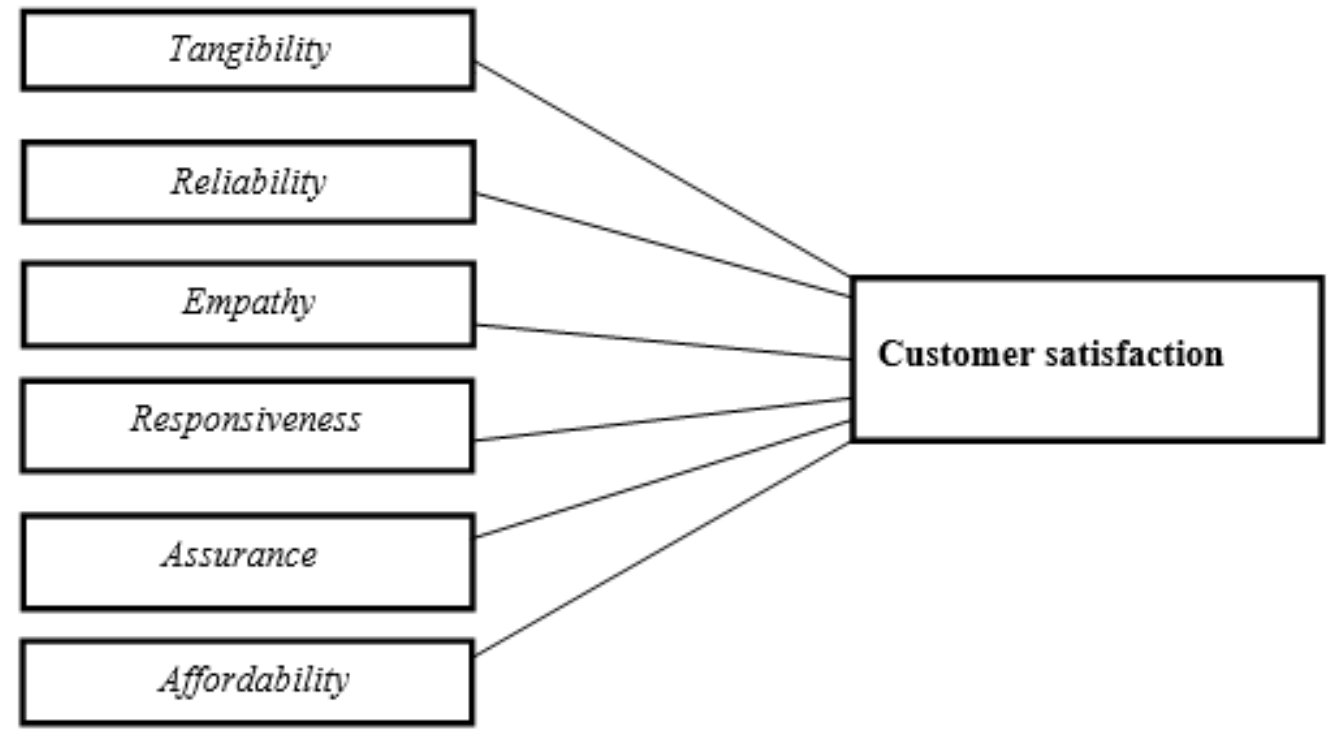

Source: Developed by the researchers based on reviewed literature

\section{Materials and Methods}

\subsection{Data Sources}

The data for this study was collected through a self-administered structured questionnaire. A questionnaire is the most common tool to investigate a similar aim. The first part of the questionnaire was the demographic profile of respondents, the second part incorporated the 25 items modified SERVPERF questions and the third part included questions about overall service quality and overall customer satisfaction. All items were rated by respondents on a five-point Likert scale. The questionnaires were distributed in person by the well-trained data collectors and the proper follow up and an assistant was provided by the researchers.

The study has relied on the modified SERVPERF model which is more suitable than the SERVQUAL model in scrutinizing customers' perceptions of service quality. Besides, SERVQUAL is less desirable as it uses 
the difference scores (i.e., Perception - Expectation) which in turn cause more confusion and fatigue for survey participants. Thus, through the utilization of a modified SERVPREF model the study has conducted a descriptive and explanatory survey using a structured questionnaire.

\subsection{Sampling and Sampling Procedure}

Addis Ababa light rail transit has two lines i.e East-West line from Ayat to Torhailoch and the South-North line from Kality to Menelik II Square. The two lines have a total number of 39 stations. From these stations, 22 stations stretched from North-South and the remaining 17 stations in the second line. Form a total of 39 stations a total of 10 stations were selected based on researchers' judgment on the bases of proportional distance from the main terminals. Accordingly 6 stations from the North-South (Minilik II, Abenet, Mexico, Temenja Yazh, Nefas Silk I, and Kality) and 4 stations form East-West (Torhailoch, Hayahulet II, Management Institute, and Ayat) were targeted in the study.

The study used Cochran's (1963) sample size determination formula for an unknown or large sample to come up with a sample size of 384 . Ones the sample size was determined the total sample was equally apportioned to the 10 stations resulting in 39 judgmentally selected passengers in each station. To insure representativeness, respondents who were found at the stations during peak, off and weekend time were inculcated. Target respondents of this study were passengers that are within the age range between 15 and 65 , living in Addis Ababa and experienced in using light rail transport. The ages range 15 to 65 years old was chosen because people at this age have a routine commute travel behavior. From the age of 15, teenagers usually have to go to a school that is not in their neighborhood. After the age of 65, people usually do not have routine behavior because of pension.

\subsection{Reliability and Validity}

Cronbach's alpha is used in this study to assess the internal consistency of the data collection instrument. Cronbach's alpha (coefficient alpha), ranges in value from 0 , meaning no consistency, to 1 , meaning complete consistency (all items yield corresponding values). The result of the overall scale reliability coefficient alpha for this study is 0.917 and the coefficient alpha for all six items of modified service quality found to be more than 0.702 . The measures exceed the usual recommendation of alpha $=0.70$ for establishing the internal consistency of the scale. To ensure validity, survey questions were reviewed by experts and it was proven that scales had an adequate face and content validity. Moreover, empirical studies evaluating validity, reliability, and methodological soundness of service quality scales point to the superiority of the SERVPERF scale. Therefore, one can conclude that research instrument used in this study is valid and reliable.

\subsection{Data Analysis}

Ones that questionnaire was collected and returned, the researchers coded and entered data into Statistical Package for the Social Sciences version 23 (SPSS-23) software. Moreover, specific data analysis techniques were utilized given the nature of each specific objective of the study is different.

1) To find out the level of service quality and customers' satisfaction in AA-LRT,

For this objective, the appropriate descriptive statistics (means and standard deviations) were used to examine passengers' appraisal of the quality of service provided by the transit and their satisfaction with the services provided.

2) To examine the relationship between perceived service quality and customers satisfaction in AA-LRT,

To meet this second objective, the Pearson correlation test was conducted to study the relationship between perceived service quality dimensions and overall customer satisfaction.

3) To analyze the effect of service quality dimensions on customer satisfaction.

For objective three, a multiple regression analysis was carried out to examine the direction and strength of relationships among the constructs.

\section{Results and Discussion}

\subsection{Level of Service Quality and Customers Satisfaction}

The above table shows respondents' perception towards modified service quality dimensions, overall service quality, and general customer satisfaction. As seen in table 1 below, the perception of respondents on assurance is 3.02 in terms of a mean score which is better than other service quality dimensions and slightly greater than moderate. This is followed by responsiveness, affordability, and tangibility with an approximately moderate mean score of 3.0, 2.98, and 2.94 respectively. On the other hand, empathy and reliability are the least perceived values form the modified service quality dimensions with a mean score of 2.92 and 2.9 respectively. 
Table 1: Descriptive Statistics

\begin{tabular}{|lrcc|}
\hline & Descriptive Statistics & \\
\hline & $\mathrm{N}$ & $\mathrm{Mean}$ & Std. Deviation \\
\hline Tangibility & 370 & 2.9356 & .51063 \\
\hline Reliability & 370 & 2.9038 & .49060 \\
\hline Responsiveness & 370 & 3.0074 & .53797 \\
\hline Assurance & 370 & 3.0230 & .56861 \\
\hline Empathy & 370 & 2.9189 & .56924 \\
\hline Affordability & 370 & 2.9820 & .51386 \\
\hline Overall service quality & 370 & 2.92 & .696 \\
\hline Customers satisfaction & 370 & 2.90 & .683 \\
\hline
\end{tabular}

Source: Survey data, 2019

The mean perception of the customers on the assurance is relatively good (3.02) which shows that as far as trustworthiness, courtesy, friendly approach, knowledge of the staff and installing a sense of safety among commuters during travel are concerned customers perceive that the service is slightly greater than moderate (average). Similarly, the service quality perception of respondents on responsiveness (3.0), affordability (2.98), and tangibility (2.94) are the second, third, and fourth better dimensions with a mean score of approximately moderate.

While responsiveness, as a SERVPRF dimension, is related to informing customer their rights and responsibilities and the willingness, ability, and promptness of employees in their response to customers' queries; affordability measures reasonableness of the fare given the service, availability of weekly, monthly or season based ticketing and comparative fairness of the fair in comparison with other forms of transportation. Similarly, tangibility (2.94) reflects the comfort of train station facilities, cleanliness of the inside environment of the train, professional appearance of the staff, accessibility of visual display materials, the comfort of seats, deployment of modern equipment.

However, customers' perception of the remaining SERVPRF dimension, empathy (2.91), and reliability (2.9) is the rate below moderate (average). This indicts that the quality of the service for customers with special needs and attention (disables, pregnant, children, and elderly) and accuracy of ticketing services, punctuality, safety/security of service, staff shows interest in solving problems and overall correctness of the service are found to below.

Generally, the mean perception of respondents with overall service quality and customer satisfaction is below moderate with a mean value of approximately 2.9 each. Assessing these mean scores in light of Anton's (1997) three zones of perception of service performance, Addis Ababa Light Rail Transit customers' satisfaction index is slightly lower than moderate which is below the tolerance (acceptance) zone.

\subsection{Correlation Analysis between SERVPRF Dimensions and Customer Satisfaction}

Correlation analysis is used to check the strength of the relationship among various variables. In this study, the correlation of SERVPRF dimensions, overall service quality and level of customers' satisfaction is analyzed. The value of the correlation coefficient could take values between -1 and 1 which means the coefficient is ranging from being negatively correlated (-1) to uncorrelated (0) and to positively correlated (1). The Pearson correlation result $\mathrm{r}(\rho)$ indicates the magnitude of relationships in the following categorization (Dancey \& Reidy, 2004): the relationship is weak if the coefficient is between 0.10 and 0.3 , moderate when it is between 0.40 and 0.6 and strong when it is between 0.70 and 1.00 . When the correlation analysis coefficient is equal to 1 , the Pearson result considers it as perfect correlation.

As can be seen from the table below, all service quality dimensions have a positive relationship with overall service quality and customer satisfaction through the magnitude of the relationship differ among service quality dimensions. All of the dimensions, reliability, assurance, tangibility, affordability, and empathy have a high coefficient value of $0.824,0.821,0.811,0.779$, and 0.702 respectively showing the existence of a significant and strong relationship with overall service quality. 
Table 2: Pearson Correlation among Measures

\begin{tabular}{|c|c|c|c|c|c|c|c|c|}
\hline \multicolumn{9}{|c|}{ Correlations } \\
\hline & $\begin{array}{l}\text { Customers } \\
\text { Satisfaction }\end{array}$ & $\begin{array}{l}\text { Overall } \\
\text { Service } \\
\text { Quality }\end{array}$ & Tangibility & Responsiveness & Assurance & Reliability & Empathy & Affordability \\
\hline $\begin{array}{l}\text { Customers } \\
\text { Satisfaction }\end{array}$ & 1 & & & & & & & \\
\hline $\begin{array}{l}\text { Overall Service } \\
\text { Quality }\end{array}$ & $.895^{* *}$ & 1 & & & & & & \\
\hline Tangibility & $.877^{* *}$ & $.811^{* *}$ & 1 & & & & & \\
\hline Responsiveness & $.808^{* *}$ & $.778^{* *}$ & $.763^{* *}$ & 1 & & & & \\
\hline Assurance & $.842^{* *}$ & $.821^{* * *}$ & $.804^{* *}$ & $.803^{* *}$ & 1 & & & \\
\hline Reliability & $.880^{* *}$ & $.824^{* *}$ & $.829^{* *}$ & $.821^{* *}$ & $.840^{* *}$ & 1 & & \\
\hline Empathy & $.745^{* *}$ & $.702^{* *}$ & $.713^{* *}$ & $.687^{* *}$ & $.729^{* * *}$ & $.742^{* *}$ & 1 & \\
\hline Affordability & $.844^{* * *}$ & $.779^{* *}$ & $.809^{* *}$ & $.768^{* *}$ & $.803^{* * *}$ & $.820^{* *}$ & $.711^{\text {*** }}$ & \\
\hline
\end{tabular}

**. Correlation is significant at the 0.01 level (2-tailed).

Source: Survey data, 2019

On the other hand, all service quality dimensions have a positive relationship with the level of customer satisfaction albeit with varying degrees. In light of this, reliability, tangibility, affordability, assurance, responsiveness, and empathy have a correlation coefficient values of $0.88,0.87,0.844,0.842,0.808$, and 0.745 respectively showing the existence of a significant and strong relationship with customer satisfaction. The implication of the analysis result is that the better the quality of service with all the six modified quality dimensions, the higher the level of Addis Ababa light rail customer satisfaction.

Finally, the relationship between the overall service quality and customer satisfaction is also analyzed using correlation analysis. The result shows that overall service quality and customer satisfaction have both positive and significant relationship with a correlation coefficient value of 0.895 . In effect this confirms the statements:

a. Parasuraman, Zeithmal, and Berry $(1985,1988)$ point out that service quality and customer satisfaction are closely related.

b. By Cronin and Taylor (1992) explaining service quality is an antecedent of satisfaction.

Table 3: Results of Multiple Regressions between Tangibles, Reliability, Responsiveness, Assurance, Empathy, Affordability and Customer satisfaction

\begin{tabular}{|c|c|c|c|c|c|c|c|}
\hline \multicolumn{8}{|c|}{ Coefficients $^{a}$} \\
\hline \multirow[t]{2}{*}{ Model } & \multicolumn{2}{|c|}{$\begin{array}{l}\text { Unstandardized } \\
\text { Coefficients }\end{array}$} & $\begin{array}{l}\text { Standardized } \\
\text { Coefficients }\end{array}$ & \multirow[t]{2}{*}{$\mathrm{t}$} & \multirow[t]{2}{*}{ Sig. } & \multicolumn{2}{|c|}{$\begin{array}{l}\text { Colinearity } \\
\text { Statistics }\end{array}$} \\
\hline & $\mathrm{B}$ & Std. Error & Beta & & & Tolerance & VIF \\
\hline (Constant) & -.759 & .079 & & 9.646 & .000 & & \\
\hline Tangibility & .323 & .047 & .241 & 6.803 & .000 & .227 & 4.400 \\
\hline Reliability & .272 & .056 & .195 & 4.862 & .000 & .177 & 5.649 \\
\hline Responsiveness & .041 & .042 & .033 & .993 & .321 & .265 & 3.779 \\
\hline Assurance & .030 & .045 & .025 & .667 & .505 & .205 & 4.869 \\
\hline Empathy & .045 & .033 & .038 & 1.396 & .163 & .388 & 2.579 \\
\hline Affordability & .180 & .045 & .136 & 3.970 & .000 & .244 & 4.093 \\
\hline
\end{tabular}

Source: Survey data, 2019

As table 3 shows, the tolerance values of all independent variables are above 0.1 and the VIF values are below 10 which the two values together confirm none existence of multicollinearity problem in the regression analysis under consideration. Moreover, tangibility, reliability, responsiveness, assurance, empathy, and affordability (the independent variables) impact on the dependent variable (customers' satisfaction) are positive as values of coefficient $\beta$ confirm. This means service quality dimensions contribute positively and significantly to customers' satisfaction. Tangibility, Reliability, and affordability have a relatively higher impact with the value of $\beta 0.241,0.195$, and 0.136 on customers' satisfaction followed by empathy, responsiveness, and assurance with the value of $\beta 0.038,0.033$ and 0.025 respectively. Empathy, responsiveness, and assurance have the lowest positive and insignificant impact on customer satisfaction. 


\section{Conclusion and Recommendations}

\subsection{Conclusion}

Urban light rail transport service delivery by Addis Ababa Light Rail Transit has been scrutinized in this study. Modified service quality dimensions particularly the SERPREF was used as a construct to measure customer satisfaction of the same entity by applying various statistical tools. It merits wrap up the finding in the forthcoming statements so that their implication will be pinpointed clearly.

In the descriptive analysis portion of the paper, customers' perceptions measured in terms of mean values. In line with this except for two quality dimensions, assurance, and responsiveness, where the satisfaction is slightly greater than moderate and moderate respectively, for the remaining quality dimensions customers are not satisfied with a mean score below moderate (3.0). Hence, customers of Addis Ababa Light rail transit are not satisfied with affordability, tangibility, reliability, and empathy dimensions. With regards to the overall services quality and customer satisfaction, the customers are not satisfied with Addis Ababa Light rail transit urban transport service delivery. However, as the mean scores are closer to moderate (around 2.9) with planned intervention it is possible to reach at least a moderate level of satisfaction.

The correlation analysis of service quality dimensions (tangibility, reliability, responsiveness, assurance, empathy, and affordability) shows, they all are positively significantly correlated to the quality of the overall service. The inference of this is that the better the quality of service with all the six modified quality dimensions, the higher the level of Addis Ababa light rail customer satisfaction. Besides, all service quality dimensions have a positive and significant relationship with the level of customer satisfaction. The strongest relationship is observed on reliability and tangibility. The overall service quality correlation with customer satisfaction is very strong and significant $(0.895)$. In conclusion, focusing on tangibility and responsiveness is necessary to fill the gap the correlation coefficient showed which would bring value addition to the customer service and ultimately secure a better level of customer satisfaction.

Regarding the effect analysis, it is found out that independent variables (service quality dimensions) have a significant impact on customers' satisfaction (dependent variables) but with varying degrees. From this, it is clear that Addis Ababa light rail transit can improve customers' satisfaction by working on quality.

\subsection{Recommendations}

In the service delivery process, Addis Ababa Light rail transit is not as empathetic as customers require. As clearly indicated in the quality dimension of empathy, Addis Ababa Light rail transit has to know the best interest of its customer and attempt to address it. Hence, the company has to revisit its manner of service delivery for customers with special needs and the friendliness of the service to all segments of the society (disables, pregnant, children, and elderly). To this end, it is necessary to give attention to individual customer interests and requirements rather than apply, "one fits all" approach.

In the same token, the reliability of rail service delivery was found to be below moderate. This implies that the accuracy of ticketing services, punctuality, safety/security of service, staff interest in solving problems, and overall correctness of the service are found to be low. Hence, the organizations should strive to fulfill promises and pay attention to the results.

The service quality perception of respondents on responsiveness, affordability, and tangibility was rated approximately moderate. To improve the modest score of responsiveness the company should work on the willingness; ability and promptness of employees in their response to customers' queries and in effectively communicating customers' rights and responsibilities. Similarly to improve the moderate perceived quality score of affordability which measures reasonableness of the fare given the service, availability of weekly, monthly, or season based ticketing the company has to commensurate service quality vis a vis the fare and design alternative ticketing package. Likewise, tangibility which reflects the comfort of train station facilities, cleanliness of the inside environment of the train, accessibility of visual display materials, comfort of seats, and deployment of modern equipment has scored approximately moderate perceived quality. To improve the tangibility score the company has to make timely maintenance of train facilities and visual display materials.

It is a well-established fact that satisfied customers are keys to higher economic returns \& long-term business success (Kristensen et al. as cited in Munusamy et.al, 2010). As this study confirms, in Addis Ababa Light rail context service quality is the biggest component that impacts customer satisfaction. The management of Addis Ababa Light rail transit has to give major attention to quality to bring about a better satisfaction level.

\section{References}

Anton,J.(1997). Call Center Management by the Numbers, Purdue University press, Annapolis, MD

Berhan, E., Beshah, B. and Kitaw, D. (2013). Performance Analysis on Public Bus Transport of the City of Addis Ababa. International Journal of Computer Information Systems and Industrial Management Applications, 5, pp. 722-728.

Cochran, W.G. (1963). Sampling Techniques, Wiley, New York. 
Cronin, J.J. and Taylor, S.A. (1992). "Measuring service quality: a re-examination and extension", Journal of Marketing, Vol. 56, July, pp. 55-68.

Dancey, C. and Reidy, J. (2004) Statistics without Maths for Psychology: using SPSS for Windows. Prentice Hall, London.

Fenta, T. M. (2014). Demands for urban public transportation in Addis Ababa. Journal of Intelligent Transportation and Urban Planning, 2(3), pp. 81-88.

Gebeyehu, M. and Takano, S. (2007). Diagnostic Evaluation of Public Transportation Mode Choice in Addis Ababa. Journal of Public Transportation, 10(4), pp. 27-50.

Habtamu Gebeyehu. (2017). Analyze factors influencing passengers' satisfaction in Addis Ababa city Light Rail Transit Service, A thesis submitted to the school of graduate study prepared for partial fulfillment of the requirements of Master of Business Administration, Addis Ababa University

Haileyesus Alebacew. (2016). Assessment on Determinants of Passengers' Satisfaction: A Case Study on Addis Ababa Light Rail Transit Service, A Thesis Submitted in Partial Fulfillment of the Requirement for the Degree of Masters of Arts in social Psychology, Addis Ababa University.

Kumar A, Barrett F (2008). Africa infrastructure country diagnostic, stuck in traffic: urban transport in Africa. World Bank, January (2008).

Munusamy, J. ,Chelliah, S. and Mun, H.W. (2010). Service Quality Delivery and Its Impact on Customer Satisfaction in the Banking Sector, International Journal of Innovation, Management and Technology, Vol. 1, No. 4, pp. 399

Parasuraman, A., Zeithaml, V., \& Berry, L.L. (1988). SERVQUAL: A multiple-item scale for measuring customer perceptions of service quality. Journal of Retailing, 64(1): 12-40.

Peter, C. (2006). "Terms in the UK" http://www.thetrams.co.uk/tramsinuk.php. Retrieved 22 Feb 2018

Rodrigue, J.P (2017), The Geography of Transport Systems $\left(4^{\text {th }}\right.$ ed $)$ New York: Routledge

SABA Engineering P.L.C. (2005), Urban Transport Study and Preparation of Pilot Project for Addis Ababa. Addis Ababa, Ethiopia: Unpublished.

Wondifiraw, Z., Kibret, H. and Wakaiga, J. (2015). Ethiopia (2015): African Economic Outlook. Addis Ababa, Ethiopia: African Development Bank.

World Bank (2015). Addis Ababa, Ethiopia: Enhancing Urban Resilience. City Strength: Resilient Cities Program. Washington DC.

World Bank (2008). Cities on the Move: A World Bank Urban Transport Strategy Review. United States of America: the World Bank, Washington Dc. 